\title{
Survival potential of Phytophthora infestans sporangia in relation to environmental factors and late blight occurrence
}

\author{
Olanya Ocen Modesto ${ }^{1}$, Mohd Anwar ${ }^{2}$, Zhongqi He ${ }^{3}$, Robert Philip Larkin ${ }^{4}$, \\ Charles Wayne Honeycutt ${ }^{5}$
}

${ }^{1}$ USDA-ARS, Eastern Regional Research Center, Wyndmoor, PA 19038, USA

${ }^{2}$ North Carolina A\&T State University, Greensboro, NC 27411, USA

${ }^{3}$ USDA-ARS, Southern Regional Research Center, New Orleans, LA 70124, USA

${ }^{4}$ USDA-ARS, New England Plant, Soil and Water Laboratory, Orono, ME 04469, USA

${ }^{5}$ USDA-NRCS, Washington, D.C. 20250, USA

Received: September 9, 2015

Accepted: February 24, 2016

\begin{abstract}
Potato is an important crop globally and late blight (Phytophthora infestans) often results in severe crop loss. The cost for late blight control can be in excess of $\$ 210$ million in the United States. We utilised a non-parametric density distribution analysis of local temperature $(T)$ and relative humidity $(R H)$, from 2005 to 2009, to assess and validate sporangia survival potential using survival model and late blight risks during the potato cropping season at Presque Isle, in the northern part of the state of Maine, USA. Modelbased analyses showed that ambient temperatures of $3-30^{\circ} \mathrm{C}$ and $\mathrm{RH}$ values of $45-100 \%$ were conducive for sporangia survival. Disease outbreaks and risk periods coincided with a high sporangia survival probability (15-35\%). Due to the omission of solar radiation $(S R)$ in the computation of survival potential in previous research, we applied a Cox proportional model to estimate the probability of sporangia survival [i.e. hazard at a specific time $H(t)$ ] as a function of baseline hazard $\left(H_{0}\right)$ and the influencing parameters. The model is: $H(t)=H_{0}(t) \times \exp (0.067 E T+0.138 T+0.083 R H+0.001 S R)$ where $E T$ is exposure time. The survival model indicated that $R H(\beta=0.083)$ and $T(\beta=0.138)$ were significant $(\mathrm{p}<0.05)$ factors in sporangia survival in comparison to $S R(\beta=0.001)$. The hazard ratio, indicative of sporangia survival risk, varied with the predictors. For the unit increase of $T$, sporangia survival hazard increased by 1.148 times. The Cox model and sporangia hazard probabilities can be used for short-term disease forecasts based on the risk period most conducive for pathogen survival and targeted fungicide applications for optimum late blight management.
\end{abstract}

Key words: climatic variables, Cox hazard model, Phytophthora infestans, potato, sporangia, survival, tomato

Mention of trade names or commercial products in this publication is solely for the purpose of providing specific information and does not imply recommendation or endorsement by the United States Department of Agriculture (USDA) or North Carolina A\&T State University of similar ones not mentioned. USDA is an equal opportunity employer.

\section{Introduction}

Potato (Solanum tuberosum L.) is grown in over 100 countries throughout the world (He et al. 2012). Potato late blight, caused by the oomycete Phytophthora infestans (Mont.) de Bary, is one of the most destructive plant diseases in potato and tomato production regions of the world (Birch and Whisson 2001; Fry 2008; Olanya et al. 2010, 2012a). Globally, potato losses attributed to late blight have been estimated in excess of $\$ 3.2$ billion (Haverkort et al. 2008). In the United States, the economic impact of late blight experienced by potato producers has often resulted from devastation of the crop due to foliar and tuber blight infections. Consequently, potato growers in the United States accrued revenue losses of approximately $\$ 210.7$ million of which about $\$ 77$ million were costs associated with fungicide use for disease control (Guenthner et al. 2001)

In the state of Maine, in northeastern United States, potato cultivation has been an important component of agricultural production (Halloran et al. 2013). Recent outbreaks of late blight in the state (Table 1) resulted in significant economic impacts. Concerns arose over current approaches for prevention and management of late blight outbreaks. The diversity of pathogen genotypes has been a significant factor in enhancing late blight epidemics. The variation in winter temperature conditions throughout the region also has favored pathogen survival in some areas.

Late blight epidemics have been influenced by inocula (sporangia, zoospores, mycelia, or oospores), suitable environmental conditions, and susceptible hosts during the cropping season (Erwin and Ribeiro 1996). Potato late blight has two phases of the disease cycle: the foliar blight and tuber blight phases. The foliar phase of late blight is initiated when sporangia, dispersed by wind from an infect- 
Table 1. Dates of potato plant emergence, and first outbreak of late blight (Phytophthora infestans) in field plots at local Presque Isle experimental plots, and statewide in Maine, USA during the 2004 to 2009 cropping years

\begin{tabular}{cccc}
\hline Year $^{\mathrm{a}}$ & $\begin{array}{c}\text { Potato } \\
\text { cultivar }\end{array}$ & $\begin{array}{c}\text { First emergence } \\
\text { of experimental } \\
\text { potato plants }^{\mathrm{b}}\end{array}$ & $\begin{array}{c}\text { First outbreak } \\
\text { in the state of } \\
\text { Maine }^{\mathrm{c}}\end{array}$ \\
\hline 2004 & Shepody & June 14 & July 26 \\
2005 & Shepody & June 25 & July 29 \\
2006 & Shepody & June 6 & July 14 \\
2007 & Shepody & June 21 & July 28 \\
2008 & Shepody & June 8 & July 17 \\
2009 & Shepody & June 4 & June 25 \\
\hline
\end{tabular}

${ }^{a}$ cropping year during which field data of blight occurrence on potato were obtained

bdate at which over $80 \%$ of potato crop had emerged in the experimental plot

cfirst known occurrence of late blight based on the scouting reports of the Maine Cooperative Extension Service at Presque Isle

ed plant, lands on foliage or stems. The plant hosts for P. infestans may include tomato (Lycopersicum esculentum L.), solanaceous weeds like hairy nightshade (Solanum sarrachoides Sendt.), and others (Erwin and Ribeiro 1996).

In the presence of moisture (water) and suitable temperatures $\left(3\right.$ to $\left.27^{\circ} \mathrm{C}\right)$, sporangia germinate, and infection of foliage or stem tissues occurs. Lesion expansion, sporangia production, and spore maturation are dependent on suitable temperatures, relative humidity and moisture, rainfall or water (Crosier 1934; Hartill 1990). When mature sporangia are disseminated through aerial wind dispersal onto potato and other suitable host plants, infection occurs and the disease cycle (foliar phase of blight) is repeated. The life cycle from plant infection to production of new sporangia can be completed within seven days under optimum environmental conditions. Temperature and relative humidity are also crucial for survival of
P. infestans sporangia in an ambient environment, potato canopy, or foliar debris (Michaelides 1985).

The tuber blight phase of late blight pathosystem consists primarily of infection of potato tubers in field soil and the subsequent tuber development in storage environments (Olanya et al. 2009a). Under field conditions, potato tubers may be infected by sporangia dispersed from symptomatic foliage and deposited into the soil. Rainfall, irrigation water, as well as defoliated diseased leaves may deposit sporangia onto the soil surface. Depending on cultural practices and the soil environment (moisture, temperature, soil type and structure), sporangia may be passively deposited into the soil and tuber infection may occur. When tubers are harvested, non-symptomatic diseased tubers, may be transported to storage along with healthy tubers. In storage these non-symptomatic diseased tubers may persist until used as seed during potato plantings and may be the sources of inocula for late blight in Maine.

The meteorological factors suitable for late blight development are: temperature $(T)$, relative humidity $(R H)$, and rainfall (irrigation) or leaf wetness duration. These factors impact various stages of pathogen development. Air temperature has been reported to impact sporangia germination (Crosier 1934), infection of foliage or stems, and lesion development (Hartill et al. 1990), as well as spore production (Sato 1994). An optimum temperature range of 15 to $22^{\circ} \mathrm{C}$ and an $R H$ in excess of $90 \%$ are known to favor blight development (Krause et al. 1975). Due to the significance of meteorological factors for late blight development in Maine and elsewhere, synoptic weather maps and models have been used in forecasting late blight and timing of fungicide applications to manage late blight (Krause et al. 1975; Olanya et al. 2012a, b). High precipitation and $R H$ increases the potential for late blight and conversely, high temperatures, low rainfall and $R H$ (drought stress) would lower the potential for disease intensity.

The potato production or cropping period ranges from May to September. Disease occurrences may often be within this period (Fig. 1). Therefore, assuming the

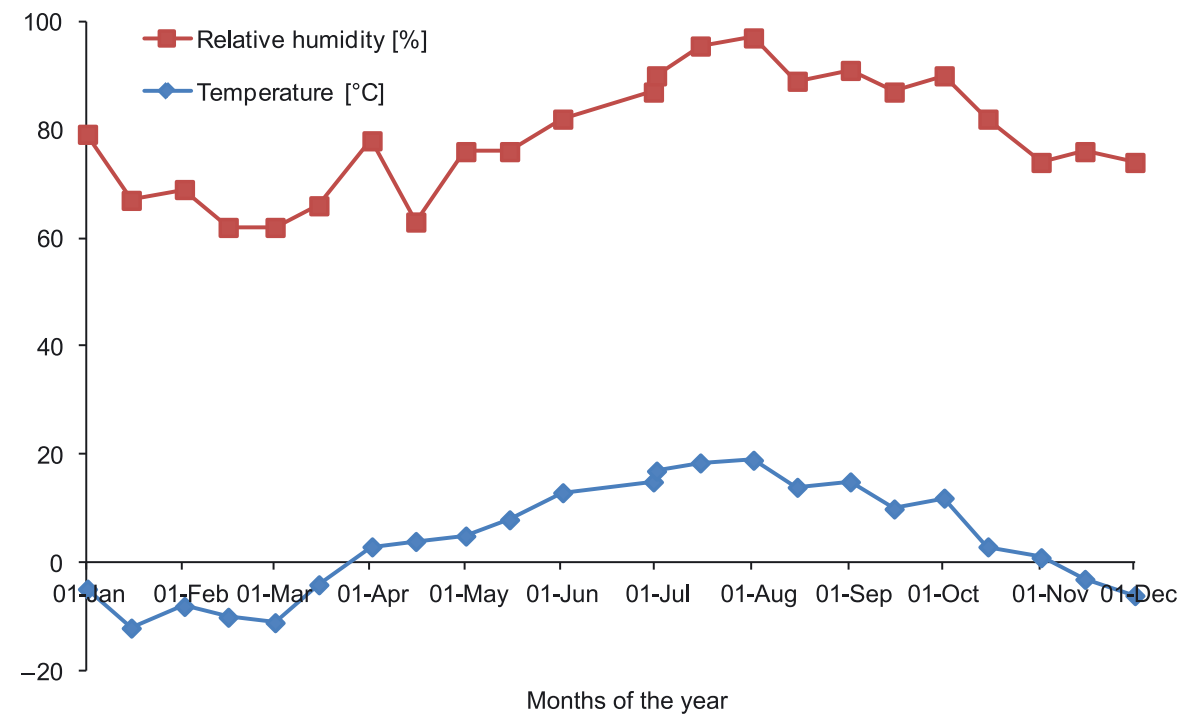

Fig. 1. Seasonal cycle of temperature and relative humidity recorded at the USDA-ARS cropping systems field site at Presque Isle, Maine. The 2005-2008 data was summarised at 3-hour resolution, and a 7-day smoothing window was used to compute the seasonal cycle shown above 
presence of $P$. infestans inocula, the potential period of sporangia production is expected to coincide with that of potato production. The following ways are used to control pathogen inocula: through the use of certified disease-free seed tubers, host-resistance, cultural practices, and judicious use of protective chemicals, yet disease spread can still result through wind dissemination of sporangia from neighboring regions or incidental movement of infected plants. Therefore, periodic occurrence of potato late blight and other diseases have been observed in Maine production regions during the last several years (Groves 2002; Olanya et al. 2009a, 2015). The outbreaks of late blight from 2005 to 2009 indicate disease reoccurrence over a multiyear period and potential significance to this production region (Table 1).

Sporangia of $P$. infestans are crucial for perpetuation of late blight, therefore their survival has been the subject of numerous investigations. Based on previous studies, $R H$ and $T$ of the environment are major determinants of sporangia longevity (Crosier 1934). Desiccation of sporangia has been reported as the primary factor limiting sporangia survival or longevity. A published report has also shown that sporangia viability in the potato canopy can occur in the $T$ of 3 to $30^{\circ} \mathrm{C}$ (Crosier 1934), provided that the $R H$ of the environment is favorable (50 to $100 \%$ ). Research investigations on the survival or viability of sporangia of $P$. infestans in different soil types (Andrivon 1994), on surface water (Porter and Johnson 2004), and on leaflets or foliar debris (Lima et al. 2009) have been conducted in attempts to quantify the relationships of survival potential to disease outbreaks. Temperature and $R H$ have been shown to be major variables affecting viability or survival of sporangia (Michaelides 1985). The survival of sporangia of $P$. infestans may be adversely affected by solar radiation (Mizubuti et al. 2000; Sunseri et al. 2002). The exposure of sporangia for a 3-hour duration on sunny days reduced germination and a one hour exposure of sporangia on sunny days reduced viability by $95 \%$ (Mizubuti et al. 2000). Duration of exposure, direct sunlight, and daytime were reported as contributing factors to sporangia survival (Sunseri et al. 2002).

An understanding of the meteorological factors of potato late blight, the application of theoretical models to location-specific contexts, and determining the potential for use of weather forecasts were important considerations (Hamill et al. 2006). So as to understand the sporangia survival probabilities in Maine and Northeastern United States and the relationship of these sporangia survival probabilities with the seasonal development of meteorological variables of $T$ and $R H$, the simulation of the sporangia survival model of Michaelides (1985) was used. The model synthesizes the primary information regarding the biology of the oomycete relative to the late blight cycle and incidences. Additionally, we applied a quantitative model to assess the survival of $P$. infestans sporangia as impacted by solar radiation $(S R), T$, and $R H$. Therefore, the objectives of this research were to:

1) evaluate a model-based quantitative assessment of the survival potential of $P$. infestans sporangia based on the meteorological factors for a potato field at Presque Isle, Maine during a five year period;

2) develop a sporangia survival function in relation to $T$, $R H, S R$, and exposure time in potato crop.

\section{Materials and Methods}

\section{Theoretical model for sporangia survival}

The model (Michaelides 1985) was used to compute theoretical survival curves for sporangia of $P$. infestans in relation to late blight risk and environmental conditions conducive for sporangia survival at Presque Isle. Presque Isle is representative of the potato cropping region in Maine. The model calculates sporangia survival, using hourly data for air $\mathrm{T}$ and $\mathrm{RH}$ at 3-hour intervals. Sporangia survival is considered within a $T$ range of $3-30^{\circ} \mathrm{C}$. The model is expressed as (Michaelides 1985):

$$
S S P=T I N X^{R H I N X}
$$

where: SSP - the sporangia survival probability over a 3-hour interval; TINX - T index and RHINX - RH index.

The $T$ and $R H$ indices were derived from sporangia longevity studies (Crosier 1934). The probability that sporangia survives after a three-hour exposure in the ambient environment (using 3-hour average $T$ and $R H$ ) is computed from the above equation 1 using the following factor indices (Michaelides 1985):

$$
\operatorname{TINX}=\left\{\begin{array}{llc}
1.1 & \text { if } & 3.0 \leq T<7.5 \\
1.12 & \text { if } & 7.5 \leq T<12.5 \\
2.0 & \text { if } & 12.5 \leq T<22.5 \\
1.12 & \text { if } & 22.5 \leq T<30.0
\end{array}\right.
$$

and

$$
\text { RHINX } \begin{cases}1 & \text { if } 45 \leq R H<55 \\ 2 & \text { if } 55 \leq R H<65 \\ 3 & \text { if } 65 \leq R H<75 \\ 4 & \text { if } 75 \leq R H<85 \\ 5 & \text { if } 85 \leq R H<95 \\ 5 & \text { if } R H \geq 95\end{cases}
$$

In this model, SSP is reduced to zero when $T<3^{\circ} \mathrm{C}$ or $\geq 30^{\circ} \mathrm{C}$, or when $R H<45 \%$. The model provided an efficient parametrisation of the meteorological factors and translation to sporangia survival probabilities.

\section{Cox proportional hazard model}

Published data (Sunseri et al. 2002) showed that SR may affect the survival of $P$. infestans sporangia. To assess the relationship of sporangia survival and other environmental factors, the theoretical survival of sporangia as a function of ambient $T, R H$, and $S R$, was modeled using microclimatic data (2005 to 2009) from Presque Isle, ME, USA. The Cox proportional hazard model is used in survival analysis to assess the importance of various covariates in the survival times of individuals through a hazard function. The quantitative impacts of various explanatory variables are assessed on the lifetime variable. The hazard model assigns the probability that a particular individual has an event (expiration). The basic assumption is that the hazard for an individual is based on two parts: 
baseline hazard function and covariates in the exponent part of the equation along with their respective unknown parameters, $b$. The impact of a covariate could be zero $(b=0)$ meaning that the particular covariate has no association with survival time. A positive coefficient value $(b>0)$ of a covariate indicates that the hazard of death increases with the covariate. On the other hand, a negative coefficient value $(b<0)$ indicates that the covariate is associated with a lower hazard of death. The model was applied to evaluate the effects of several risk factors on the maximum pathogen survival. The maximum pathogen survival is defined as the time to non-viability or death of sporangia.

The proportional hazard model used is defined as:

$$
H_{i}(t)=H_{0}(t) \times \exp \left(\beta_{1} X_{1}+\beta_{2} X_{2}+\beta_{3} X_{3}+\ldots+\beta_{1} X_{1}\right)
$$

where: $H_{i}(t)$ - the hazard function of individual sporangium $i$ at time $t ; H_{0}(t)$ - the baseline hazard at time $t$; $X_{1}$ - the vector of covariate values (predictor variables) corresponding to the $i$-th individual; $\beta$ - is the vector of coefficients to be estimated when the model fits the data.

The baseline hazard function does not depend on covariate values but only on time $t$. In this paper, hazard function corresponds to the probability of the death of $P$. infestans sporangia or being non-viable when all four predictor variables [exposure time $(E T), T, R H$, and $S R$ ] are zero. The relationships of ET to other variables (ambient temperature, $R H, S R$, and maximum survival time) were evaluated based on published data on $P$. infestans sporangia survival (Mizubuti et al. 2000; Sunseri et al. 2002).

\section{Microclimate in potato cropping experiments, Presque Isle, ME (2005-2009)}

Microclimatic variables were monitored continuously and recorded at hourly intervals at Presque Isle by using Watchdog data loggers (Model 450, Spectrum Technologies, Plainfield, IL, USA) from 2005 to 2009. Air temperature and $R H$ were recorded using a temperature/RH sensor. A pyranometer sensor was used to record $S R$. Rainfall was recorded with a tipping bucket rain gauge. Leaf wetness, soil moisture and soil $T$ were recorded with leaf wetness, soil water mark, and soil temperature sensors, respectively. The $T$ and $R H$ sensors were deployed within potato plots in the Potato Cropping Systems plots at Presque Isle, ME. The height of the microclimatic sensors was adjusted based on potato growth, to maintain a position within the potato canopy. Soil water mark sensors were installed $15 \mathrm{~cm}$ below the soil surface in field plots. The pyranometer sensor was positioned above the potato canopy.

\section{Data analysis}

The dataset collected for $T$ and $R H$ as well as $S R$ was compiled for the 2005-2009 Presque Isle, ME (US) cropping years, and used to assess sporangial survival. Seasonal microclimatic data was compiled using Microsoft Excel and Visual Basic Programs. The sporangia survival probability was computed from 2005 to 2009 based on hourly outputs of $T$ and $R H$ using the survival model (Michaeli- dis 1985). The joint probability distribution of $T$ and $R H$ were computed using the non-parametric density estimation approach by the Statistical Analysis System (Bowman and Azzalini 1997 ;SAS Institute, Inc., Raleigh, NC). To assess the effects of ambient $T, R H$, and SR on sporangia survival, the Cox proportional hazard model outlined in equation 4 was used. The model was fitted to data to generate survival function and regression coefficients for sporangia survival as a function of exposure time, $T, R H$, and $S R$ values by using the Statistical Analysis System (SAS Inc., version 9.3., Cary, NC). The regression coefficients, associated standard errors, and hazard ratios were also computed, and significance of parameters were computed at $\mathrm{p}<0.05$.

\section{Results}

The seasonal variation of $T$ and $R H$ in relation to the potato cropping cycle at Presque Isle, ME is shown in figure 1 . The seasonal window which corresponded to the potato-cropping cycle highlighted the average $\mathrm{T}$ and $\mathrm{RH}$ conditions during the April-September period that favors sporangia survival. A comparison of the temperature and relative humidity data, revealed that the diurnal mean ambient temperatures from potato canopy at Presque Isle (Table 2) differed slightly from that in the published data (Sunseri et al. 2002). At Presque Isle, the mean ambient temperatures ranged from 11.77 to $21.77^{\circ} \mathrm{C}$. But the mean ambient temperatures ranged from 13 to $29.25^{\circ} \mathrm{C}$ in the experiments of Sunseri et al. (2002). The average $R H$ values also varied substantially (57.68 to $94.07 \%$ ) and were greater in data collected from the Presque Isle site compared to those from Sunseri et al. (2002) which were considerably lower and ranged from 20 to $46 \%$. Similarly, the mean solar radiation data values of $0.01 \mathrm{~W} \cdot \mathrm{m}^{-2}$ (night hours) to $553.62 \mathrm{~W} \cdot \mathrm{m}^{-2}$ (daytime) were also lower at Presque Isle (Table 2) compared to data from Sunseri et al. (2002) in which the solar radiation values ranged from 0 $\mathrm{W} \cdot \mathrm{m}^{-2}$ (night hours) to $839 \mathrm{~W} \cdot \mathrm{m}^{-2}$ (daytime hours).

The probability distribution of $T$ and $R H$ is shown for the five-year period: 2005 to 2009 (Fig. 2). The empirical probability density indicating the relative frequency in which $T$ and $R H$ vary during a long-term period for the months of April to September of the potato cropping seasons in northern Maine, US, is also shown.

It was indicated by the SSP computations and the summary statistics for the relative incidence of low-tohigh probabilities, that approximately $10 \%$ of sporangia had a survival probability of $10-16 \%$, while $15 \%$ of sporangia had a survival probability of $16-30 \%$. When we examined the temporal variations in SSP and compared it to the time (dates) for first outbreak of late blight in Maine, the periods where SSP values increased dramatically (shown in gold color) were indicative of greater survival probabilities (Fig. 3). The data showed surges in SSP which were consistent with favorable conditions for sporangia survival and coincided with the actual dates of the first late blight outbreak or occurrence in Maine.

In contrast to the above, the survival potential of $P$. infestans in the potato canopy computed using temperature and $R H$ values for a 24 -hour period and based on the sur- 
Table 2. Mean temperature $(T)$, relative humidity $(R H)$, and solar radiation $(S R)$ data from potato field plots at Presque Isle, ME (2004-2009) from which the hazard function for the survival of Phytophthora infestans sporangia were computed ${ }^{a}$

\begin{tabular}{|c|c|c|c|c|}
\hline $\begin{array}{c}\text { Time } \\
\text { [hours of the day] }\end{array}$ & $\begin{array}{c}\text { Temperature }^{\mathrm{b}} \\
{\left[{ }^{\circ} \mathrm{C}\right]}\end{array}$ & $\begin{array}{c}\text { Relative } \\
\text { humidityc } \\
{[\%]}\end{array}$ & $\begin{array}{c}\text { Solar } \\
\text { radiation } \\
{\left[\mathrm{W} \cdot \mathrm{m}^{-2}\right]}\end{array}$ & $\begin{array}{c}\text { Diurnal } \\
\text { survival potentiale } \\
{[\%]}\end{array}$ \\
\hline 100 & $13.21 \pm 0.18$ & $90.98 \pm 0.37$ & $0.01 \pm 0.00$ & - \\
\hline 200 & $12.73 \pm 0.17$ & $92.15 \pm 0.35$ & $0.01 \pm 0.00$ & - \\
\hline 300 & $12.31 \pm 0.16$ & $93.14 \pm 0.33$ & $0.01 \pm 0.00$ & 13.93 \\
\hline 400 & $11.95 \pm 0.18$ & $94.04 \pm 0.30$ & $0.33 \pm 0.04$ & - \\
\hline 500 & $11.77 \pm 0.17$ & $94.07 \pm 0.31$ & $7.69 \pm 0.68$ & - \\
\hline 600 & $12.04 \pm 0.15$ & $92.29 \pm 0.35$ & $34.23 \pm 1.63$ & 13.90 \\
\hline 700 & $13.12 \pm 0.16$ & $87.76 \pm 1.42$ & $97.14 \pm 0.95$ & - \\
\hline 800 & $14.54 \pm 0.17$ & $82.49 \pm 2.47$ & $207.97 \pm 4.75$ & \\
\hline 900 & $15.99 \pm 0.17$ & $76.63 \pm 1.53$ & $334.91 \pm 6.74$ & 9.89 \\
\hline 1,000 & $17.39 \pm 0.16$ & $71.01 \pm 1.59$ & $437.54 \pm 8.15$ & - \\
\hline 1,100 & $19.12 \pm 0.25$ & $66.24 \pm 1.64$ & $518.74 \pm 9.17$ & - \\
\hline 1,200 & $19.62 \pm 0.22$ & $62.59 \pm 1.67$ & $553.92 \pm 9.34$ & 4.79 \\
\hline 1,300 & $20.42 \pm 0.18$ & $61.16 \pm 1.34$ & $553.96 \pm 9.35$ & - \\
\hline 1,400 & $20.90 \pm 0.22$ & $58.55 \pm 0.78$ & $521.17 \pm 8.99$ & - \\
\hline 1,500 & $21.23 \pm 0.19$ & $57.68 \pm 1.18$ & $466.09 \pm 8.28$ & 3.52 \\
\hline 1,600 & $21.27 \pm 0.24$ & $58.38 \pm 0.74$ & $377.44 \pm 7.28$ & - \\
\hline 1,700 & $21.01 \pm 0.27$ & $60.54 \pm 1.06$ & $269.05 \pm 5.92$ & - \\
\hline 1,800 & $20.33 \pm 0.19$ & $65.25 \pm 1.72$ & $157.84 \pm 4.35$ & 4.20 \\
\hline 1,900 & $19.03 \pm 0.18$ & $72.27 \pm 1.64$ & $66.07 \pm 2.58$ & - \\
\hline 2,000 & $17.33 \pm 0.17$ & $79.15 \pm 1.53$ & $15.45 \pm 0.91$ & - \\
\hline 2,100 & $15.93 \pm 0.16$ & $83.16 \pm 0.68$ & $0.87 \pm 0.07$ & 9.37 \\
\hline 2,200 & $15.02 \pm 0.19$ & $85.83 \pm 0.48$ & $0.86 \pm 0.07$ & - \\
\hline 2,300 & $14.36 \pm 0.18$ & $87.58 \pm 0.42$ & $0.01 \pm 0.00$ & - \\
\hline 2,400 & $13.78 \pm 0.16$ & $89.51 \pm 0.39$ & $0.01 \pm 0.00$ & 13.00 \\
\hline
\end{tabular}

adata was from environmental variables (hourly values) recorded from May 16 to September 15 for a six year period (2004-2009) of the potato cropping systems experiment

bthe mean ambient temperature computed from hourly data recorded during the cropping cycle (May 16 to September 15 for a six year period). Temperature was recorded using a temperature sensor attached to a Spectrum Technologies data logger

${ }^{c}$ the mean of relative humidity $(R H)$ were computed from hourly data (May 16 to September 15 for a six year period) and quantified during the experimental period using a $R H$ sensor from a data logger

daverage solar radiation intensity data were recorded by a pyranometer sensor (data logger) deployed on a potato canopy. Data represents hourly outputs from May 16 to September 15 for a six year period

esporangia survival potential for a 24-h period computed at 3-hourly intervals based on the survival model (Michaelides 1985) 

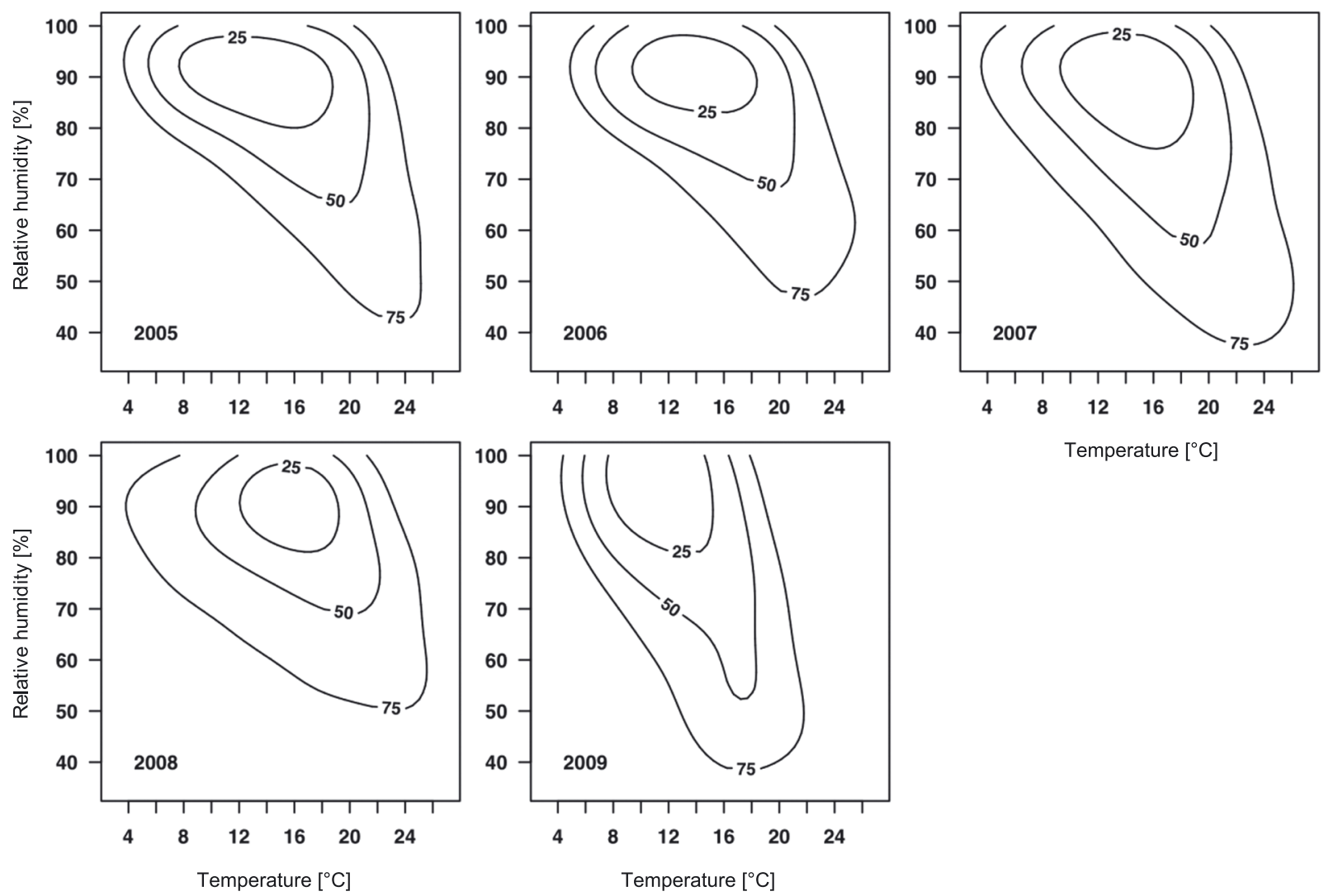

Fig. 2. The joint distribution of temperature $(T)$ and relative humidity $(R H)$ recorded during the potato-cropping season at Presque Isle, ME (April 1-September 30). Observations for five consecutive seasons (2005-2009) are sampled at 3-hour intervals. The empirical estimate of the joint probability distribution is based on a nonparametric density estimation approach that used bivariate Gaussian kernel with an optimal bandwidth. The contour levels represent the cumulative probability of occurrence within the region enclosed by the contour
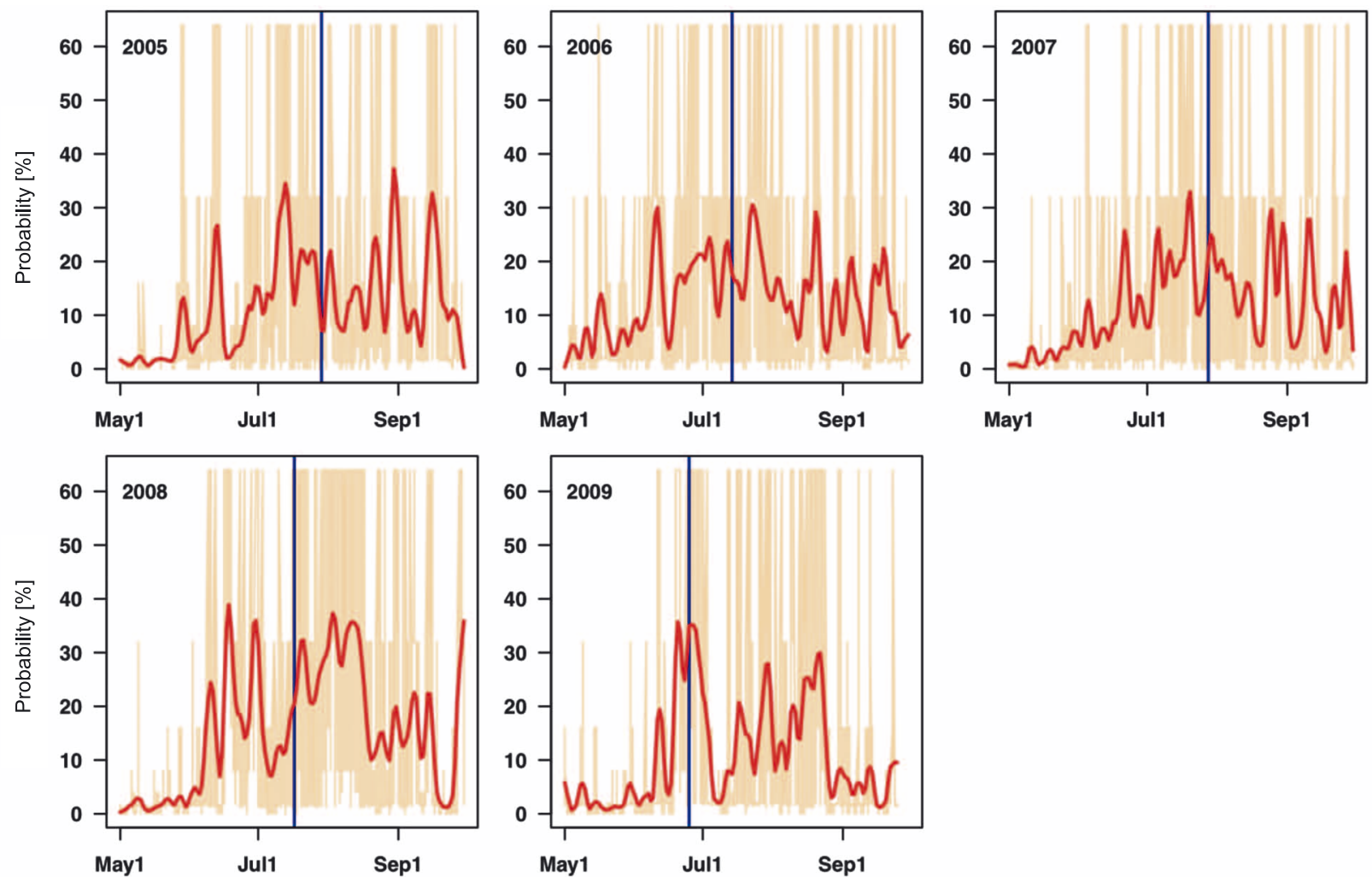

Fig. 3. The seasonal development of sporangia survival probabilities (SSP) based on the observed temperature and relative humidity. The computations of the SSPS were done for each 3-hour intervals (shown in gold). A seven-day curve, shown in red, revealed the major time duration where the SSP increased dramatically (resulting from the effects of the temperature and relative humidity variations). Blue vertical lines represent the date corresponding to the first reported late blight outbreaks in the state of Maine 
Table 3. Cox regression model and goodness of fit parameters developed for the estimation of the coefficients for sporangia survival based on environmental factors, exposure time, and solar radiation

\begin{tabular}{|c|c|c|c|c|}
\hline Variables $^{\mathrm{a}}$ & $\begin{array}{c}\text { Regression } \\
\text { coefficients } \\
\qquad(\beta)\end{array}$ & $\begin{array}{c}\text { Standard } \\
\text { errors }^{b}\end{array}$ & $\mathrm{p}$-value ${ }^{\mathrm{b}}$ & Hazard ratio ${ }^{c}$ \\
\hline Exposure time [h] & 0.067 & 0.039 & 0.091 & 1.069 \\
\hline Temperature $\left[{ }^{\circ} \mathrm{C}\right]$ & 0.138 & 0.073 & $0.058^{*}$ & 1.148 \\
\hline Relative humidity [\%] & 0.083 & 0.039 & $0.033^{*}$ & 1.086 \\
\hline Solar radiation $\left[\mathrm{W} \cdot \mathrm{m}^{-2}\right]$ & 0.001 & 0.002 & $0.810 \mathrm{~ns}$ & 1.001 \\
\hline
\end{tabular}

arisk factors used in estimating sporangia survival based on the cox proportional hazard model

${ }^{b}$ standard errors and $p$-values associated with parameter estimates; ${ }^{*}=$ significant at $\mathrm{p}<0.05$, and ns $=$ non-significant

'Hazard ratio is the increase in risk for survival based on the increase of predictors

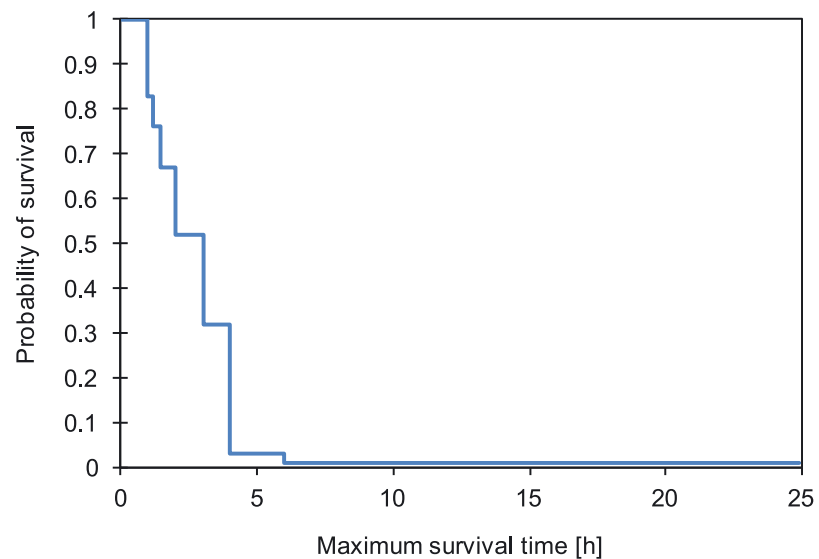

Fig. 4. The proportion of surviving sporangia versus time of pathogen exposure

vival model (Michaelidis 1985), showed a diurnal trend with values that peaked at night hours and decreased at daytime hours (Table 2). The average survival potential for 3-hourly intervals ranged from $3.52 \%$ between 1 to 3:00 p.m. to $13.93 \%$ at night hours (1 to 3:00 a.m.).

Due to the potential effect of $S R$ on the viability and survival of sporangia of $P$. infestans (Sunseri et al. 2002), the Cox regression model was applied and assessed for the effects of ambient temperature, relative humidity, and solar radiation on the theoretical survival of $P$. infestans sporangia. Sporangia survival functions were best described by the Cox regression model (Table 3). The goodness of fit of the data and regression coefficients were significant $(p<0.05)$. Using the values of $\beta$, the sporangia survival function was best described as follows:

$H(t)=H_{0}(t) \times \exp (0.067 E T+0.138 T+0.083 R H+0.001 S R)$,

where: $H(t)$ - the hazard function at time $t ; H_{0}(t)$ - the baseline hazard function (probability of non-viable or dead sporangia), exp - exponential function, ET - exposure time (h), $\mathrm{T}$ - temperature $\left({ }^{\circ} \mathrm{C}\right), \mathrm{RH}$ - relative humidity $(\%)$, and $S R-$ solar radiation $\left(\mathrm{W} \cdot \mathrm{m}^{-2}\right)$.

The regression model indicated that $T$ and $R H$ were the most significant hazards to sporangia survival (Table 3 ).

The proportion of sporangia survival versus time is shown in figure 4 . The probability of surviving sporan-

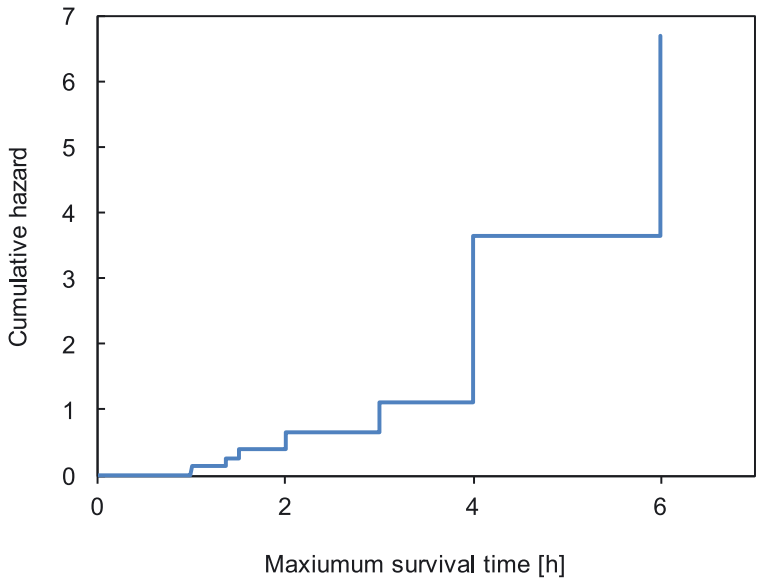

Fig. 5. Cumulative hazard and maximum survival time for sporangia. The cumulative hazard is derived as a function of the negative log of survival probability

gia ranged from 0 to 1 , while the maximum survival time ranged from 1 to $6 \mathrm{~h}$. The survival curve implies that the risk of sporangia death increases as survival time approaches the maximum value (Fig. 4). The cumulative hazard (the negative log of the survival probability) versus maximum survival time is shown in figure 5 . In this graph, the rate of cumulative hazard between 4 to $6 \mathrm{~h}$ increased drastically from 0 to 7 (Fig. 5).

\section{Discussion}

The concentrations of high $R H$ values were recorded in all of the years, and implied that conditions were conducive for sporangia survival and late blight occurrence in Maine. The climatic data recorded and observed for the 2009 cropping year showed a broader distribution of $R H$ compared to the 2005 to 2008 years, and indicated that climatic variations may occur from year to year. Variations in temperature and relative humidity values and their conduciveness for late blight development have been previously documented (Olanya et al. 2015). The numerically lower solar radiation, temperatures, and relative humidity values at the potato canopy at the Presque Isle site compared to published data, suggests that conditions for pathogen survival were more conducive at Presque Isle than that recorded in the published data of Sunseri et al. 2002. Thus, differences in the pathogen survival potential 
may vary between and among locations or potato production regions, depending on the temperature, humidity, and solar radiation conditions, as well as the availability of pathogen sporangia in the potato canopy.

Although seasonal data (May to September of each year) indicated that a wide range of favorable conditions for the pathogen existed during the potato cropping cycle, some differences in the shape of distributions of $T$ and $R H$ demonstrated that potential differences in the low and high SSP occurred based on the model computations. For example the diurnal cycle indicated lower values for sporangia survival probability. The seasonal trend (May to September) showed a wide range of up to a $30 \%$ survival potential. This implied that the survival model does not give a reliable estimate of pathogen survival potential. The high SSPs also indicated an increased risk of late blight outbreak; however, lower SSPs were sufficient for sporangia survival of the oomycete. Therefore, the survival probability distribution throughout the cropping season indicated positive infection potential. Previous researchers quantified the survival potential of $P$. infestans sporangia on the surface in soil and crop debris and in the ambient environment, and associated it with late blight outbreaks (Porter and Johnson 2004; Lima et al. 2009). The survival model of Michaelidis (1985) overestimated the survival potential of $P$. infestans sporangia as some of these values, particularly at seasonal levels (May to September), were much higher than the diurnal cycle or those previously reported (Mizubuti et al. 2000).

The occurrence of SSP was consistent with favorable conditions for spore survival and implied that late blight outbreaks may be expected under such conditions. Previous research that assessed the incidence of late blight on potato and tomato in Maine (Olanya et al. 2015), indicated that the frequencies of late blight outbreaks were substantially greater when temperatures and relative humidity were favorable. This is in agreement with the possibility that sporangia survival potential would be greater during such conditions. It is also possible that periods of sporangia survival probability may be utilised to complement late blight advisories, including fungicide applications based on short to medium-range weather forecasts.

Although the cox regression model showed that $T$ and RH were the most important hazards for sporangia survival, it should be pointed out that solar radiation values $\left(\mathrm{W} \cdot \mathrm{m}^{-2}\right)$ recorded during the experiments at the Presque Isle site in northern Maine, had relatively lower intensity values. This could also suggest that solar radiation of low intensity values may have limited or variable effects on pathogen survival. The hazard ratio which is indicative of the risk of sporangia survival varied with the predictors. For example, with a unit increase of $T$, the sporangium survival hazard increased by 1.148 times. It should be noted that the predictor variables contributed positively to the survival hazard. The probability of the sporangia survival time ranged from 0 to $5 \mathrm{~h}$ of exposure. This indicates that the combinations of $T, R H$, and $S R$ specified in the model, limited survival, or that sporangia viability may be expected beyond that time period.

It has been reported that $S R$ intensity may impact survival of sporangia of $P$. infestans based on the duration of exposure, and its interaction with $T$ and $R H$ (Mizubuti et al. 2000; Sunseri et al. 2002). The results differed from the above in that $T$ and $R H$ showed greater effects on the survival potential or hazards to survival and this may be attributed to location effect. For example, from the Cox proportional hazard model, $T$ and $R H$ had a greater effect on sporangia survival than $S R$ as indicated by the significance of $p$ values. The differences may be attributed to the lower values of solar radiations and higher $R H$ values obtained at Presque Isle. This could also be explained by the underlying distributions of the environmental factors as well as differences among locations. From a decision-support perspective, sporangia dispersal trajectories and survival could be important for accurate forecasts and a decision support system that reduces the deleterious impacts of late blight.

\section{Conclusions}

The variability of $T, R H$, and SSP, coincided with periods of late blight outbreaks. The model overestimated sporangia survival potential as survival probability values had a wide range (Michaelides 1985). The survival study of Sunseri et al. (2002) evaluated survival as function of temperature, weather conditions, duration of exposure, and direct or indirect sunlight exposure for short term (daytime hours). The Cox regression model which evaluated the theoretical effects of temperature, relative humidity, solar radiation and duration of exposure showed that temperatures and humidity had greater effects on sporangia survival potential than solar radiation on potato canopy, as based on data from Presque Isle. Quantitative estimates of survival potential could vary among locations due to climatic conditions. Still, the Cox model and sporangia hazard probabilities could be used for short-term disease forecasts based on the risk periods that may be highly conducive for pathogen survival and targeted fungicide applications for optimum late blight management. It should be pointed out, that quantitative data and models for pathogen survival in tubers (in the form of mycelia), in potato tubers in storage environments, and overwintering tubers and their survival in alternate hosts, have not previously been accounted for. This presents additional risks and modeling parameters associated with this type of survival coupled with pathogen survival. Sporangia addressed in this paper would provide additional insights into the survival potential of $P$. infestans and in designing effective controls.

\section{Acknowledgements}

We are thankful to Ben Lagasse, Ethel Champaco, and David Torrey for the technical and logistical assistance in conducting the field experiments and thank Dr. Shaleen Jain from the University of Maine for assistance with statistical analysis.

\section{References}

Andrivon D. 2007. Dynamics of the survival and infectivity to potato tubers of sporangia of Phytophthora infestans. Soil Biology and Biochemistry 26 (8): 945-952. 
Birch P.R., Whisson S.C. 2001. Phytophthora infestans enters the genomic era. Molecular Plant Pathology 2: 257-263.

Bowman A.W., Azzalini A. 1997. Applied smoothing techniques for data analysis: The Kernel Approach with S-Plus Illustrations, Oxford University Press, Oxford, UK, 208 pp.

Crosier W. 1934. Studies in the biology of Phytophthora infestans (Mont) de Bary. Cornell Agricultural Experiment Station Memoir: 155-203.

Erwin D.C., Ribeiro O.K. 1996. Phytophthora Diseases Worldwide. American Phytopathological Society Press, St. Paul, Minn., USA, 562 pp.

Fry W.E. 2008. Phytophthora infestans: the plant (and $R$ gene) destroyer. Molecular Plant Pathology 9 (3): 385-402.

Groves C.L. 2002. Characterization of Phytophthora infestans from Maine during 1999 to 2000. American Journal Potato Research 79 (5): 325-333.

Guenthner J.F., Michael K.C., Nolte P. 2001. The economic impact of potato late blight on US growers. Potato Research 44 (2): 121-125.

Halloran J.M., Larkin R.P., DeFauw S.L., Olanya O.M., He Z. 2013. Economic potential of compost amendment as an alternative to irrigation in Maine potato production systems. American Journal of Plant Science 4: 238-245.

Hamill T.M., Whitaker J.S., Mullen S.L. 2006. Reforecasts, an important dataset for improving weather predictions. Bulletin American Meteorological Society 87: 33-46.

Hartill W.F.T., Young K., Allan D.J., Henshall W.R. 1990. Effects of temperature and leaf wetness on the potato late blight. New Zealand Journal Crop Horticultural Science 18 (4): 181-184.

Haverkort A.J., Boonekamp P.M., Hutten R., Jacobsen E., Lotz L.A.P., Kessel G.J.T., Visser R.G.T., van der Vossen E.A.G. 2008. Societal costs of late blight in potato and prospects of durable resistance through cisgenic modification. Potato Research 51 (1): 47-57.

He Z., Larkin R.P., Honeycutt C.W. (eds.). 2012. Sustainable Potato Production: Global Case Studies. Springer, Amsterdam, The Netherlands, $539 \mathrm{pp}$.

Krause R.A., Massie L.B., Hyre R.A. 1975. BLITECAST: a computerized forecast of potato late blight. Plant Disease Reporter 59: 95-98.

Lima M.A., Maffia L.A., Barreto R.W., Mizubuti E.S.G. 2009. Phytophthora infestans in a subtropical region: survival on tomato debris, temporal dynamics of airborne sporangia and alternative hosts. Plant Pathology 58 (1): 87-99.
Michaelides S.C. 1985. A simulation model of the fungus Phytophthora infestans (Mont) De Bary. Ecological Modelling 28 (1-2): 121-137.

Mizubuti E.S.G., Aylor D.E., Fry W.E. 2000. Survival of Phytophthora infestans sporangia exposed to solar radiation. Phytopathology 90 (1): 78-84.

Olanya O.M., Plant A.B., Larkin R.P., Honeycutt C.W. 2009a. Infection potential of hairy nightshade (Solanum sarrachoides) by Phytophthora infestans and late blight implications of the alternate host. Journal of Phytopathology 157 (7-8): 427-437.

Olanya O.M., Ojiambo P.S., Nyankanga R.O., Honeycutt C.W., Kirk W.W. 2009b. Recent developments in managing tuber blight of potato (Solanum tuberosum) caused by Phytophthora infestans. Canadian Journal of Plant Patholology 31 (3): 280-289.

Olanya M., Nelson R., Hakiza J., Ewell P., El-Bedewy R., Kakuhenzire R., Namanda S., Kasheija I., Wagoire W., Ngombe B., Musoke C. 2010. Comparative assessment of pest management practices in potato production at Farmer Field Schools. Food Security 2 (4): 327-341.

Olanya O.M., Honeycutt C.W., He Z., Larkin R.P., Halloran J.M. 2012a. Early and late blight potential on Russet Burbank potato as affected by microclimate, cropping systems and irrigation management in North eastern United States. p. 43-60. In: "Sustainable Potato Production: Global Case Studies" (Z. He, Larkin R.P., Honeycutt C.W., eds.). Springer, Amsterdam, The Netherlands.

Olanya O.M., Honeycutt C.W., Tschoepe B., Kleinhenz B., Lambert D.H., Johnson S.B. 2012b. Effectiveness of SIMBLIGHT1 and SIMPHYT1 models for predicting Phytophthora infestans in north-eastern United States. Archives of Phytopathology and Plant Protection 45: 1558-1569.

Olanya O.M., Honeycutt C .W., Larkin R.P. 2015. Incidence of Phytophthora infestans on potato in Maine, 2006-2010. Journal of Plant Protection Research 55 (1): 58-68.

Porter L.D., Johnson D.A. 2004. Survival of Phytophthora infestans in surface water. Phytopathology 94 (4): 380-387.

Sato N. 1994. Effect of sporulating temperature on the limit temperature in indirect germination of sporangia of Phytophthora infestans. Annals Phytopathology Society of Japan 60: 60-65.

Sunseri M.A., Johnson D.A., Dasgupta N. 2002. Survival of detached sporangia of Phytophthora infestans exposed to ambient, relatively dry atmospheric conditions. American Journal of Potato Research 79 (6): 443-450. 